\title{
Design of Triangular and Plus Shaped Fractal Antennas for Multi-Band Applications
}

\author{
M.Satyanaryana, Ph.D \\ Md.Sirazuddin \\ P. Suma Prasanth \\ Associate Professor \\ MVGR College of Engg., MVGR College of Engg., \\ V.V.SaiArun \\ MVGR College of Engg.,
}

\section{ADVANTAGES \& APPLICATIONS}

\begin{abstract}
Heavy changes have already taken place in the field of wireless communications in $21^{\text {st }}$ century. Yet the demand for opulence and mitigated tautness is very much alive. An antenna with wider bandwidth, multiband operations and low profile characteristics is the cardinal root to all the modern day requirements. Fractal antenna fills this paucity with its unusual properties of self-similarity and multi-band behavior besides possessing the features of an ideal antenna. A multi-band antenna can be used for operating in more than one band of frequencies. This unique feature is reinforced using a triangular and plus shape fractal antenna. These two are assumed to cater the needs of the mankind with their bankable lineaments. Because of these savory properties, it is felt that this paper should deal with these two fractal types and their cornucopia applications. The ascendancy gained by fractal antennas over conventional antennas is because of the reduced size and multi-band nature. In this paper the applications and advantages of triangular and plus shaped slotted fractal antenna are dealt along with their design and radiation properties. It finds its application in the fields of medicine, military, geology and in wireless communication. The antennas are designed at a resonant frequency of $2.4 \mathrm{GHz}$ and the simulations like VSWR, return losses are calibrated at this frequency. The simulation results are observed using HFSS 12 and are verified using network analyzer.
\end{abstract}

\section{INTRODUCTION}

In modern era, man is the alter ego of luxury. A device supporting wlan, gps, gprs, bluetooth, NFC and many more is the need for the day. If an antenna is used for each lineament, the size of the desired device will tend to infinity. Besides, the other hindrances are single band performance of conventional antenna and dependence between size and operating frequency. Fractal antenna seemed to be the answer for this demand. Now the question arises what a fractal antenna is? Succinctly, an antenna with a self-similarity design to enhance the perimeter of material under the affect of electromagnetic radiations within a given total surface area or volume is called as fractal antenna. The term fractal, derived from "fractus", was coined by Mandelbrot, entails broken or irregular fragments. Radiation characteristics are greatly leveraged by the size of antenna with respect to $\lambda$. For efficacious results, the size should be in the order of $\lambda / 2$ or larger. But designing with these parameters will deteriorate the bandwidth, efficiency and gain. Multiband antenna plays its role in unriddling this conundrum.
Advantages of fractal antennas outnumber those of conventional antennas. The prime advantage of the former is its multiband behavior at reduced size. On performing iterations on the basic shape, one can obtain increased bandwidth and multi-band nature, leading to improved VSWR and return losses. The simulated results are found to be in good agreement with experimental results.

The iteration results obtained are very much necessitated in cellular communications. The self-similarity feature will help in enhancing multiband and UWB properties of antenna. Miniaturization of antenna is possible with space-filling property of the fractal antenna. Bountiful range of this antenna extends from the design of MIC components to present day cellular antennas. It can supersede the duck antennas in cellular communication.

These antennas are also used to locate oil, identify geologic faults, and possibly in predicting earthquakes. Acid rain and corrosion can be modeled using these antennas. The spring industry uses the fractal geometry to abate the testing time of strings from 3 days to 3 minutes.

\section{FRACTAL THEORY}

Fractal antenna theory, an extension of Euclidian geometry, stems from classic electromagnetic theory. The chief attributes of this antenna are self-similarity and space-filling. This self-similar nature enables similar surface current distributions for different frequencies, i.e. multiband behavior is obtained. As space filling property increases the electrical length, slenderized size can be obtained at a desired resonant frequency. In conventional micro-strip patch antennas, multiband behavior is achieved by using multiple radiating elements or reactively loaded patch antennas and the same is possible with self-similarity property in case of fractal antennas. These antennas are basically self-loading as inductance and capacitance are added without use of any external components and as a result they consist of various resonant frequencies.

Mathematically a fractal is defined based on a fractal dimension given by $\mathrm{D}_{\mathrm{s}}=\frac{\ln (\mathrm{N})}{-\ln (\gamma)}$ where $\mathrm{N}$ is number of copies of entire object and $\gamma$ is the scaling factor of each copy. 


\section{TYPES OF FRACTAL ANTENNAS}

The various types of fractal antennas are

1. Hilbert Curve fractal Dipole: Its chief characteristic is the exhibition of lower resonant frequency than any other antenna of same dimensions.

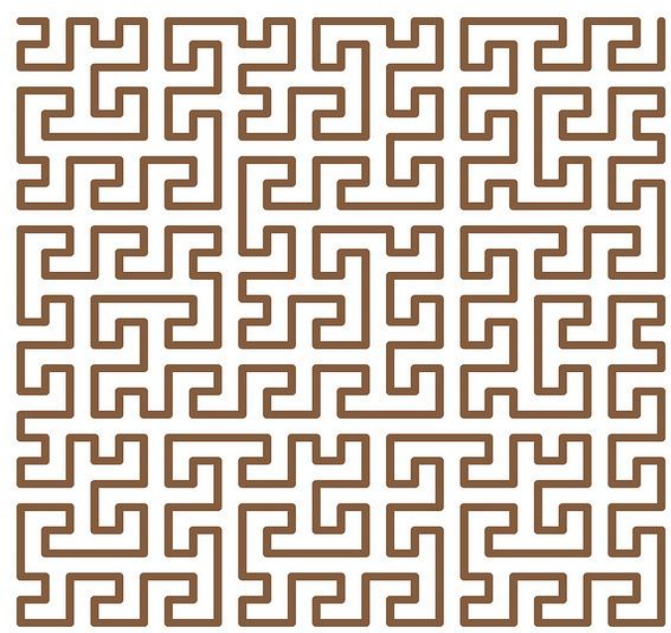

2. Koch Fractal Monopole: It is a small antenna offering characteristics which no other antenna with the same dimensions could achieve. The fractal dimension of this antenna is $\log 4 / \log$ $3 \approx 1.26$ which is lesser than Peano's apace-filling curve but greater than dimension of line.

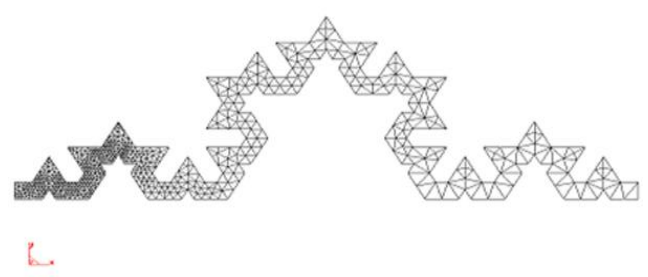

There are also few other types like triangular fractal antenna, plus shape slotted fractal antenna which we are dealing in detail.

\section{TRIANGULAR FRACTAL ANTENNA}

The triangular fractal antenna is a good example of a self-similar antenna that shows multi-band behavior. It shows several resonance bands. It has a log-periodic behavior with bands specified by a factor $\mathrm{s}=2$ and with a moderate bandwidth of $21 \%$. The antenna is matched at frequencies:

$\mathrm{f}_{\mathrm{n}}=0.26 \frac{c}{h} \mathrm{~S}^{\mathrm{n}}$ where $\mathrm{S}=2$ is $\log$-periodic constant, $\mathrm{n}$ is a natural number, $\mathrm{c}$ is the speed of light in vacuum and $\mathrm{h}$ is the height of largest TFA

The stages of construction of a fractal antenna are as show in the figure. Initially an equilateral triangle and in the next step the center triangle with vertices located at mid-points of the sides of the former triangle are removed. The triangular fractal is generated by continuous iteration in this process, an infinite number of times.

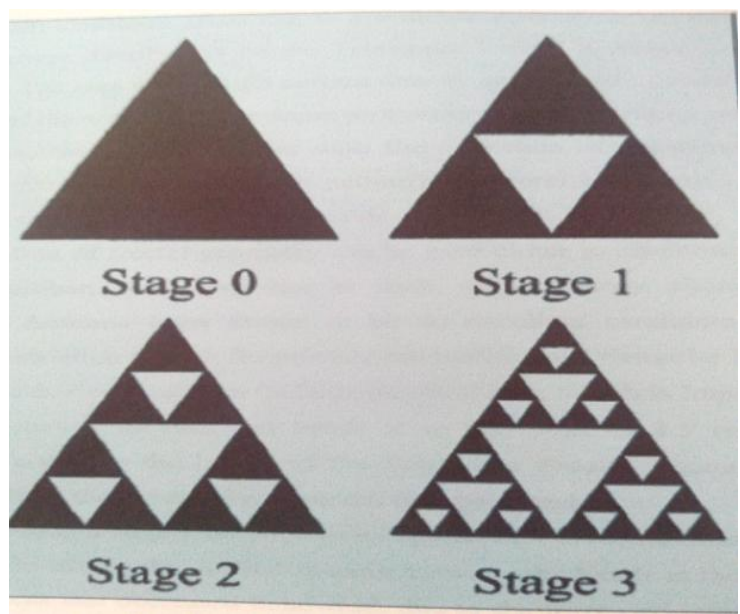

The fractal antenna is designed on the FR4 substrate with a di-electric constant of 4.4 and a thickness of $1.6 \mathrm{~mm}$.

$\mathrm{f}_{\mathrm{r}}=0.3 \cos (\alpha) \sqrt{\frac{2.5}{\varepsilon r}} \frac{c}{h} \mathrm{~S}^{\mathrm{n}}$

Where $f_{r}$ is resonant frequency, $\alpha$ is flare angle, $\varepsilon_{r}$ is relative permittivity of the substrate, $h$ is height of gasket, $\mathrm{S}$ is scale factor, $\mathrm{n}$ is iteration

$\mathrm{l}_{\mathrm{x}}=2 \mathrm{~h} \tan ((180-\propto) / 2)$ and $\mathrm{l}_{1}=\mathrm{l}_{2}=\left(\mathrm{h}^{2}+(\mathrm{a} / 2)^{2}\right)^{1 / 2}$

Where $1_{\mathrm{x}}$ is length of edge opposite the flare angle $\alpha$ and $1_{1}, l_{2}$ are the other edges

In order to calculate the side of triangular fractal antenna the following parameters are required

$\mathrm{C}=3 \times 10^{8}$

$\varepsilon_{\mathrm{r}, \mathrm{dyn}}^{*}=4.2(\mathrm{FR}-4)$

$\mathrm{L}_{\mathrm{eff}}=(\sqrt{3} . \mathrm{a}) / 2$

$\mathrm{f}_{\mathrm{r}}=2.4 \mathrm{GHz}$

From the above formulae for resonant frequency, the side of triangle is calculated as $a=32 \mathrm{~mm}$.

\section{PLUS SHAPE SLOTTED FRACTAL ANTENNA}

It is designed based on the fractal concepts for multiband behavior. A plus shaped patch is taken and is subjected to iterations. After each iteration the dimensions decrease to $1 / 3^{\text {rd }}$ of the base shape. Higher iterations show that the resonant frequencies become lower than those of zero iteration which represents a conventional plus shaped patch.

The design specifications are $€_{\mathrm{r}}=4.4$ and thickness is $1.6 \mathrm{~mm}$. The base antenna is as shown in the figure. 


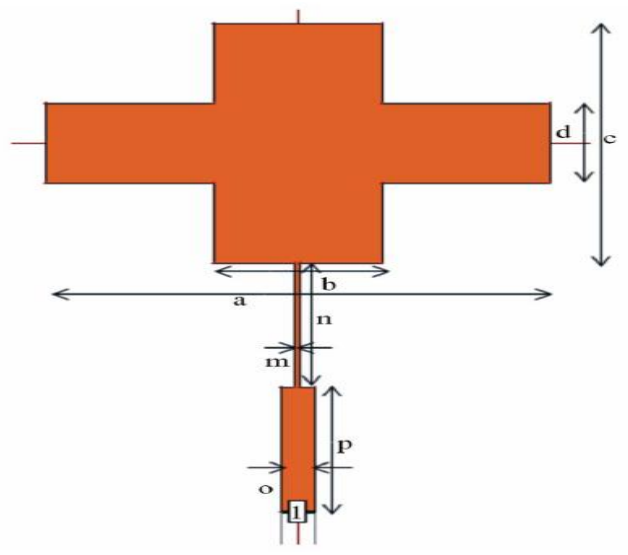

The first iteration patch is designed with four plus shapes of order $(1 / 3)$ of base shape are placed touching the base shape. The same procedure is applied for iteration 2 where the dimensions are changed as

$\mathrm{e}=(1 / 9) \mathrm{a} \& \mathrm{~g}=(1 / 9) \mathrm{c}$ also $\mathrm{f}=(1 / 9) \mathrm{b} \& \mathrm{~h}=(1 / 9) \mathrm{d}$. $\mathrm{i}=(1 / 9)$ e $\& \mathrm{k}=(1 / 9) \mathrm{g}$ also $\mathrm{j}=(1 / 9) \mathrm{f} \& \mathrm{l}=(1 / 9) \mathrm{h}$

Where $a, b, c$ and $d$ are the lengths and widths of plus shape in base antenna and $\mathrm{e}, \mathrm{f}, \mathrm{g}$ and $\mathrm{h}$ are the lengths and widths of plus shapes added to the base antenna and $i$ $, j, k$ and $l$ are the lengths and widths of the plus shapes added to the antenna in second iteration.

So with optimized design the dimensions obtained are a $=45.3 \mathrm{~mm}, \mathrm{~b}=15.1 \mathrm{~mm}, \mathrm{c}=35.4 \mathrm{~mm}, \mathrm{~d}=11.8 \mathrm{~mm}$. The length of the slot is $\mathrm{L}_{\mathrm{s}}=21.675 \mathrm{~mm}$ and width of the slot $\mathrm{W}_{\mathrm{s}}$ i.e. $\mathrm{r}=2 \mathrm{~mm}$. The dimension of the ground plan is $55 \mathrm{~mm} \times 85 \mathrm{~mm}$. A $50 \mathrm{ohm}$ SMA connector is used to feed the antenna by using micro-strip feed technique.

Optimized micro-strip line with following dimension, $\mathrm{m}$ $=0.5 \mathrm{~mm}, \mathrm{n}=18.55 \mathrm{~mm}, \mathrm{o}=3.05 \mathrm{~mm}, \mathrm{p}=18.4 \mathrm{~mm}$. The suitable feed location is obtained through optimization process by using the HFSS software.

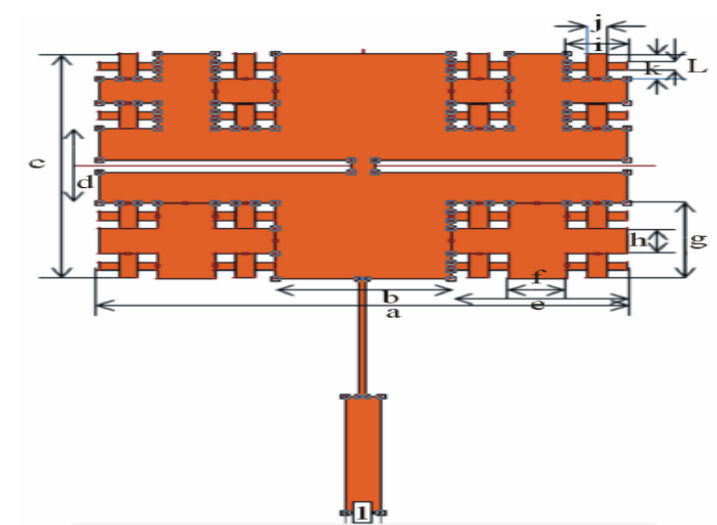

During the first iteration the resonant frequency obtained is $1.27 \mathrm{GHz}$ which is lower compared to that of 2.199 $\mathrm{GHz}$ of the base antenna and when the same antenna is slotted the resonant frequency obtained is $0.99 \mathrm{GHz}$ with a phenomenal size reduction of $79.88 \%$ and on second iteration of the same antenna multiple bands are obtained. It is found that on increasing the slot length starting from the edge of the patch, resonant frequency decreases.

\section{RESULTS}

\subsection{Triangular fractal antenna}

7.1.1 Triangular fractal antenna ( $1^{\text {st }}$ iteration) The simulation results obtained in the first iteration are

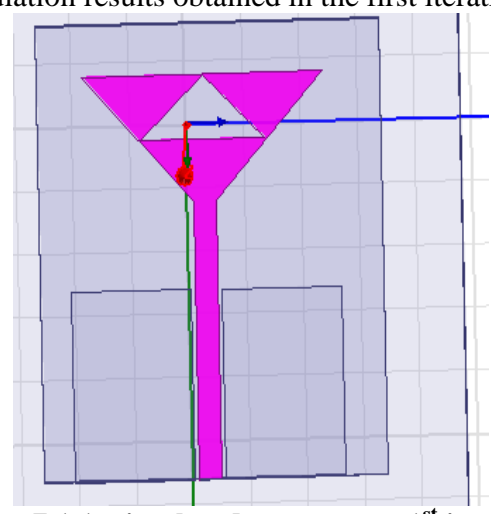

Figure 7.1.1: simulated antenna on $1^{\text {st }}$ iteration

On plotting its response, the following graphs are obtained

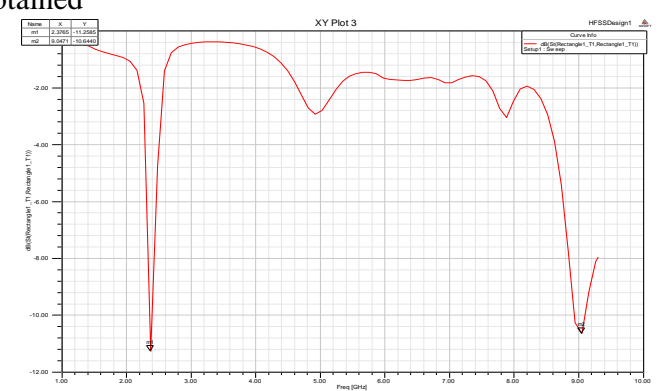

Figure 7.1.2: return loss curve of $1^{\text {st }}$ iteration

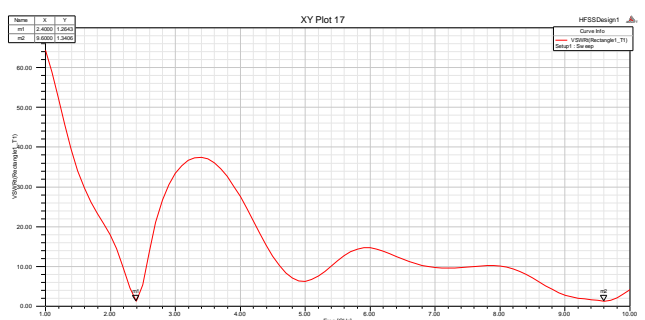

Figure 7.1.3: VSWR curve of $1^{\text {st }}$ iteration

The first iteration produced a return loss of $-11.25 \mathrm{~dB}$ at $2.37 \mathrm{GHz}$ and a return loss of $-10.6 \mathrm{~dB}$ at $9 \mathrm{GHz}$ and VSWR of 1.26 at $2.4 \mathrm{GHz}$ and 1.3 at $9.6 \mathrm{GHz}$ respectively.

7.1.2 Triangular fractal antenna $\left(2^{\text {nd }}\right.$ iteration $)$ The simulation results obtained in the $2^{\text {nd }}$ iteration of triangular fractal antenna are 


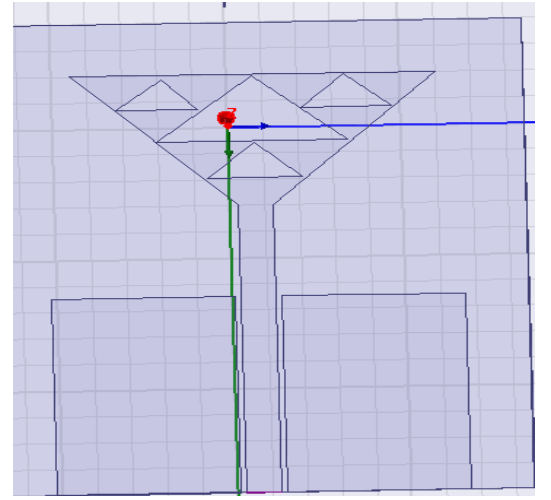

Figure 7.1.4: simulated fractal antenna on $2^{\text {nd }}$ iteration

On plotting its response, the following graph has been obtained

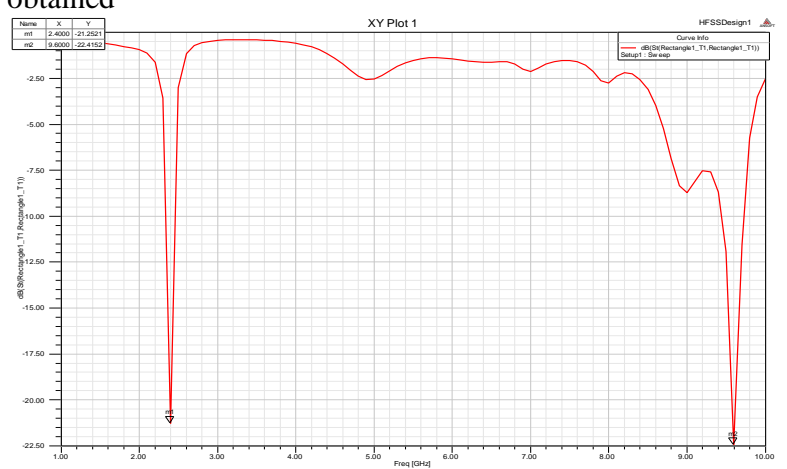

Figure 7.1.5: Return loss curve of $2^{\text {nd }}$ iteration

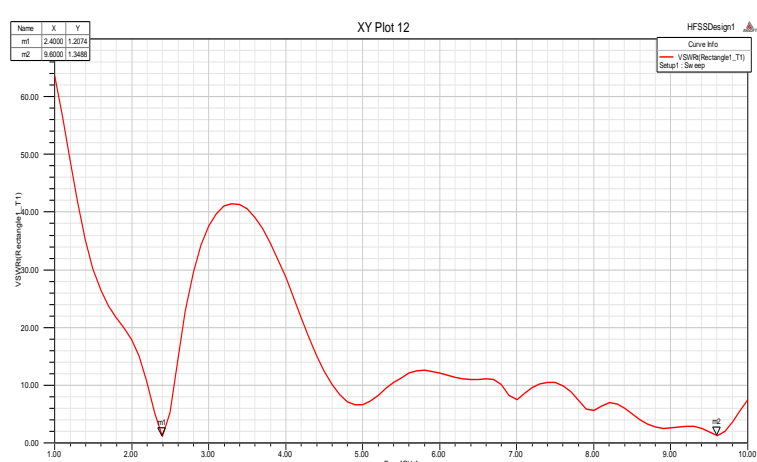

Figure 7.1.6: VSWR curve of $2^{\text {nd }}$ iteration

From the plots we can observe a return loss of $-21.2 \mathrm{~dB}$ at $2.4 \mathrm{GHz}$ and a return loss of $-22 \mathrm{~dB}$ at $9.6 \mathrm{GHz}$ and VSWR of 1.2 at $2.4 \mathrm{GHz}$ and 1.3 at $9.6 \mathrm{GHZ}$.

The results obtained when tested practically on a vector network analyzer are

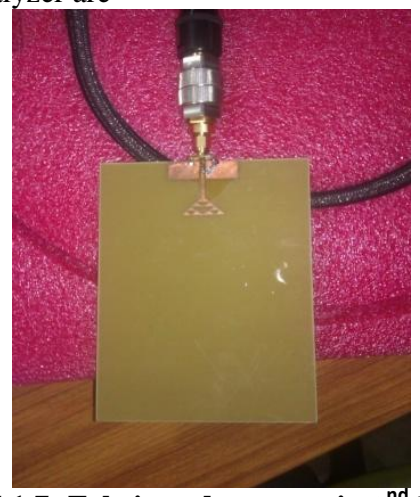

Figure 7.1.7: Fabricated antenna in $2^{\text {nd }}$ iteration

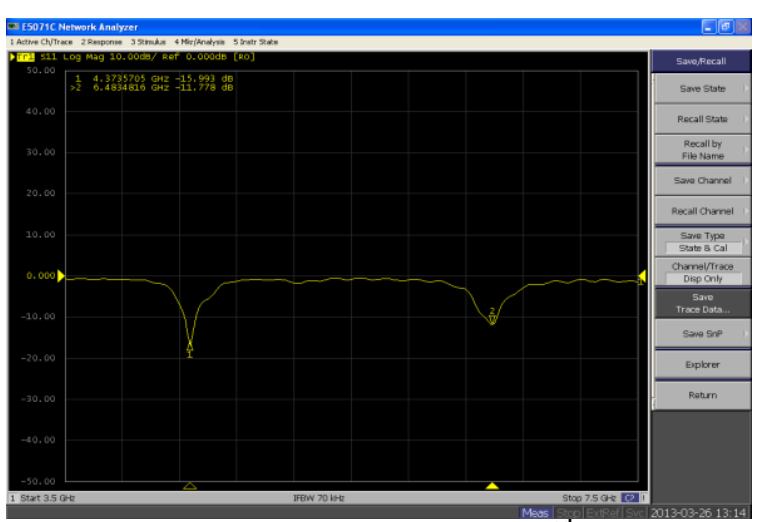

Figure 7.1.8: Return loss curve of the $2^{\text {nd }}$ iteration

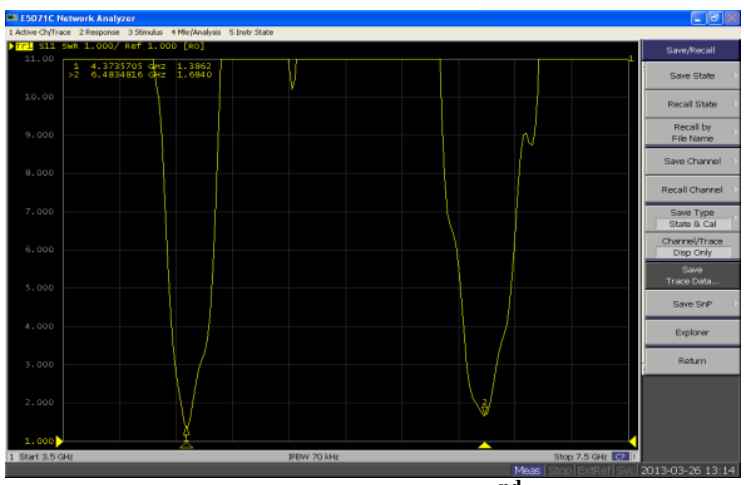

Figure 7.1.9: VSWR curve of $2^{\text {nd }}$ iteration

\subsection{Plus shaped slotted fractal antenna} 7.2.1 Plus shaped slotted fractal antenna $\left(1^{\text {st }}\right.$ iteration)

The simulation results obtained on the first iteration are

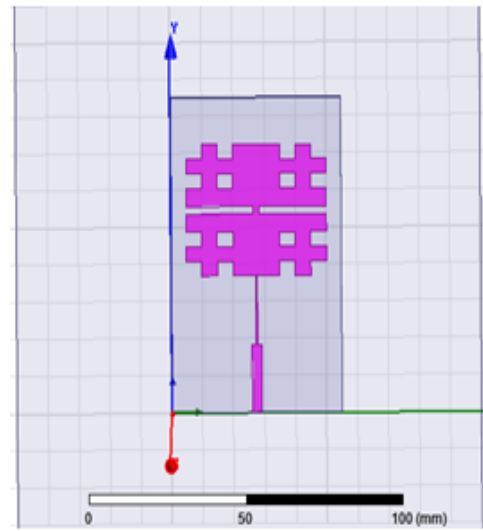

Figure 7.2.1: HFSS pattern of $1^{\text {st }}$ iteration

On plotting its response the following graphs are obtained 


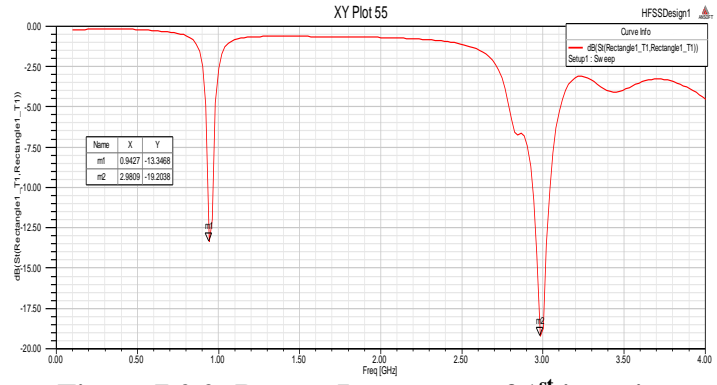

Figure 7.2.2: Return Loss curve of $1^{\text {st }}$ iteration

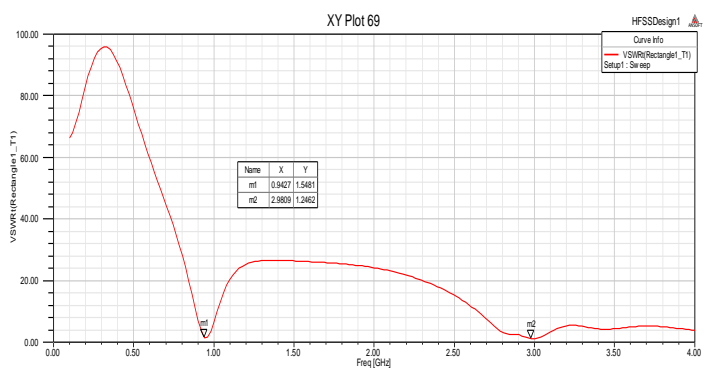

Figure 7.2.3: VSWR curve of $1^{\text {st }}$ iteration

The antenna has resonating frequencies at $0.94 \mathrm{GHz}$ and $3 \mathrm{GHz}$ and the return losses are -13.5 and -19 at these frequencies respectively where the VSWR obtained is between 1 and 2 at both frequencies.

\subsubsection{Plus shaped slotted fractal antenna $\left(2^{\text {nd }}\right.$ iteration)}

The simulation results obtained on $2^{\text {nd }}$ iteration are

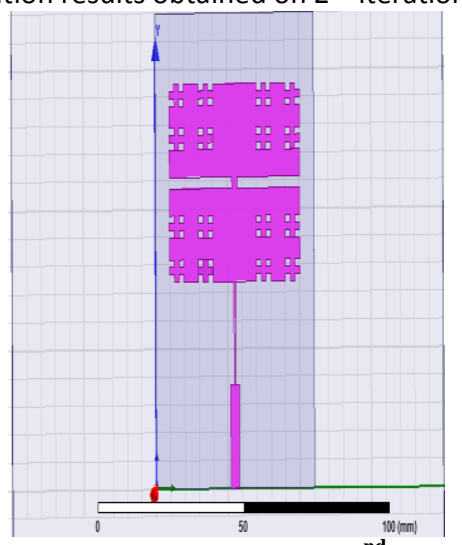

Figure 7.2.4: HFSS pattern of $2^{\text {nd }}$ iteration

On plotting its response the following graphs are obtained

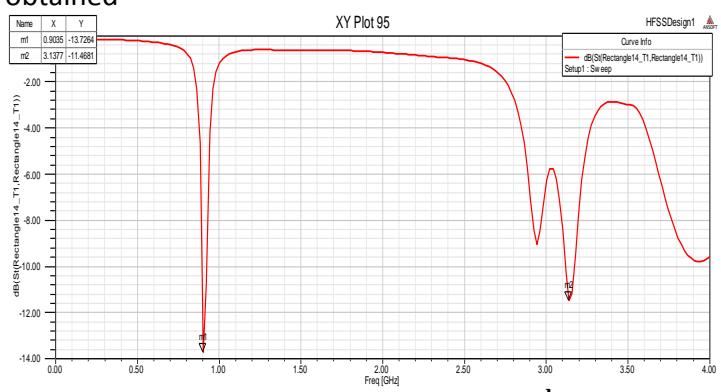

Figure 7.2.5: Return Loss curve of $2^{\text {nd }}$ iteration

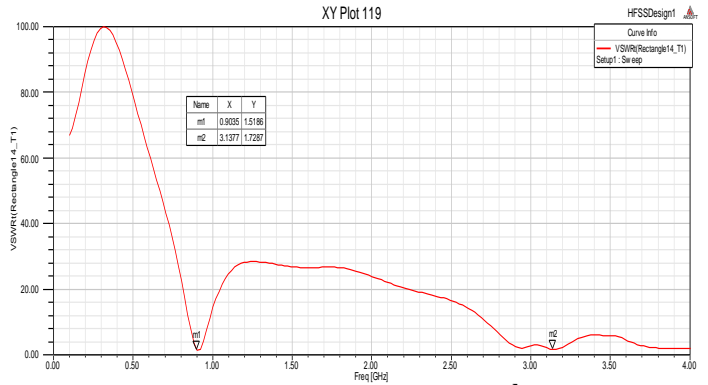

Figure 7.2.6: VSWR curve of $2^{\text {nd }}$ iteration

The antenna has resonant frequencies $0.9 \mathrm{GHz}$ and $3.13 \mathrm{GHz}$ which is dual band and the VSWR obtained at these frequencies is found to be between 1 and 2 and the return losses are -13.6 and -11.6 respectively.

The results obtained when practically tested on a vector network analyzer are

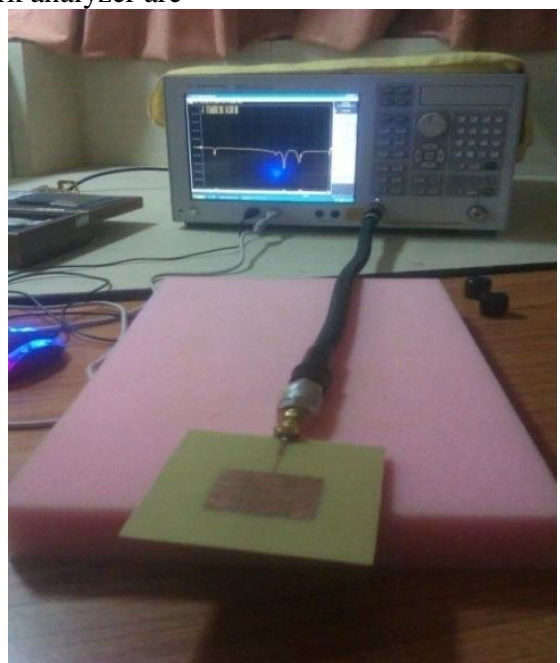

Figure 7.2.7: Fabricated antenna on $2^{\text {nd }}$ iteration

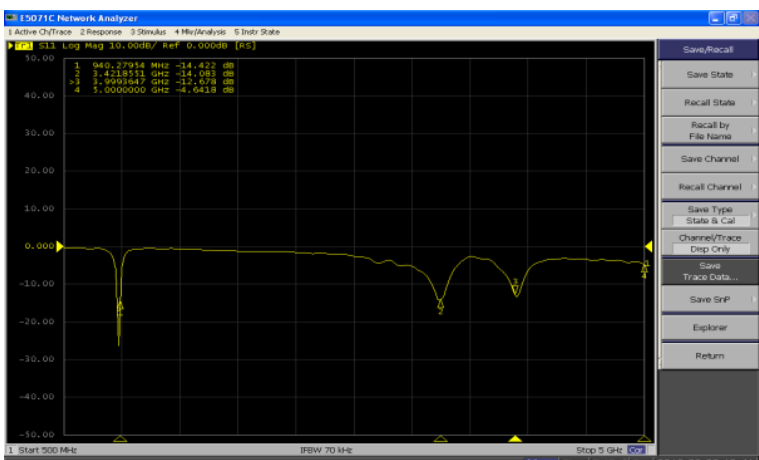

Figure 7.2.8: Return loss curve of the $2^{\text {nd }}$ iteration

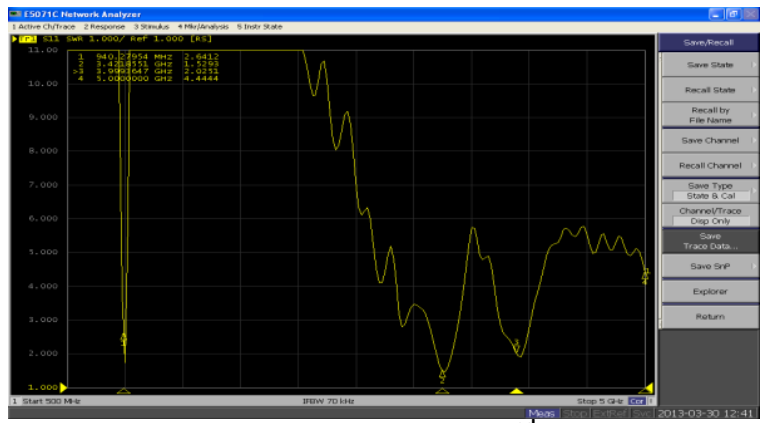

Figure 7.2.9: VSWR curve of the $2^{\text {nd }}$ iteration 


\begin{tabular}{|c|c|c|c|c|c|}
\hline \multirow[t]{3}{*}{$\begin{array}{l}\text { S. } \\
\text { no }\end{array}$} & \multirow[t]{3}{*}{ Parameter } & \multicolumn{2}{|c|}{$\begin{array}{l}\text { Triangle fractal } \\
\text { antenna }\end{array}$} & \multicolumn{2}{|c|}{$\begin{array}{l}\text { Plus shaped fractal } \\
\text { antenna }\end{array}$} \\
\hline & & & & \multirow{2}{*}{$\begin{array}{l}1^{\text {st }} \\
\text { iteration }\end{array}$} & \multirow{2}{*}{$\begin{array}{l}2^{\text {nd }} \\
\text { iteration }\end{array}$} \\
\hline & & $\begin{array}{l}1^{\text {st }} \\
\text { iteration }\end{array}$ & $\begin{array}{l}2^{\text {nd }} \\
\text { iteratio } \\
n\end{array}$ & & \\
\hline 1. & $\begin{array}{l}\text { Return } \\
\text { losses at } \\
1^{\text {st }} \\
\text { resonant } \\
\text { frequency }\end{array}$ & $\begin{array}{c}-11.2 \mathrm{db} \\
\text { at } \\
2.37 \mathrm{GH} \\
\mathrm{z}\end{array}$ & $\begin{array}{c}-21.2 \mathrm{db} \\
\text { at } \\
2.4 \mathrm{GHz}\end{array}$ & $\begin{array}{c}-13.5 \mathrm{db} \\
\text { at } \\
0.94 \mathrm{GH} \\
\mathrm{z}\end{array}$ & $\begin{array}{c}-13.6 \mathrm{db} \text { at } \\
0.9 \mathrm{GHz}\end{array}$ \\
\hline 2. & $\begin{array}{l}\text { Return } \\
\text { losses at } \\
2^{\text {nd }} \\
\text { resonant } \\
\text { frequency }\end{array}$ & $\begin{array}{c}-10.6 \mathrm{db} \\
\text { at } \\
9 \mathrm{GHz}\end{array}$ & $\begin{array}{c}-22 \mathrm{db} \\
\text { at } \\
9.6 \mathrm{GHz}\end{array}$ & $\begin{array}{c}-19 \mathrm{db} \text { at } \\
3 \mathrm{GHz}\end{array}$ & $\begin{array}{l}-11.6 \mathrm{db} \text { at } \\
3.13 \mathrm{GHz}\end{array}$ \\
\hline 3. & $\begin{array}{l}\text { VSWR at } \\
1^{\text {st }} \\
\text { resonant } \\
\text { frequency }\end{array}$ & $\begin{array}{l}1.26 \mathrm{at} \\
2.4 \mathrm{GHz}\end{array}$ & $\begin{array}{c}1.2 \mathrm{at} \\
2.4 \mathrm{GHz}\end{array}$ & $\begin{array}{c}1-2 \text { at } \\
0.94 \mathrm{GH} \\
\mathrm{z}\end{array}$ & $\begin{array}{c}1-2 \text { at } \\
0.94 \mathrm{GHz}\end{array}$ \\
\hline 4. & $\begin{array}{l}\text { VSWR at } \\
2^{\text {nd }} \\
\text { resonant } \\
\text { frequency }\end{array}$ & $\begin{array}{l}1.3 \mathrm{at} \\
9.6 \mathrm{GHz}\end{array}$ & $\begin{array}{l}1.3 \mathrm{at} \\
9.6 \mathrm{GHz}\end{array}$ & $\begin{array}{l}1-2 \mathrm{at} \\
3 \mathrm{GHz}\end{array}$ & $\begin{array}{l}1-2 \text { at } \\
3.13 \mathrm{GHz}\end{array}$ \\
\hline 5. & $\begin{array}{l}\% \\
\text { Bandwidth } \\
\text { At } 1^{\text {st }} \\
\text { resonant } \\
\text { frequency }\end{array}$ & $1.6 \%$ & $6.25 \%$ & $3.53 \%$ & $3.7 \%$ \\
\hline 6. & $\begin{array}{l}\% \\
\text { Bandwidth } \\
\text { at } 2^{\text {nd }} \\
\text { resonant } \\
\text { frequency }\end{array}$ & $2.2 \%$ & $3.15 \%$ & $3.69 \%$ & $1.7 \%$ \\
\hline
\end{tabular}

\section{RESULT ANALYSIS}

\subsection{Triangular fractal antenna}

The return loss has been improved to $-21 \mathrm{~dB}$ at $2.4 \mathrm{GHz}$ and from $-16 \mathrm{~dB}$ to $-22 \mathrm{~dB}$ at $9.6 \mathrm{GHz}$. VSWR of 1.2 at $2.4 \mathrm{GHz}$ and 1.3 at $9.6 \mathrm{GHZ}$ from $1^{\text {st }}$ iteration to $2^{\text {nd }}$ iteration.

For the $2^{\text {nd }}$ iteration, the antenna has resonating frequencies at $2.4 \mathrm{GHz}$ and $9.6 \mathrm{GHz}$ which is a dual band obtained from HFSS simulation and the practical result the antenna is resonating at the frequency $4.3 \mathrm{GHz}$ and $6.5 \mathrm{GHz}$ which is also a dual band. The deviation obtained is due to disturbances.

\subsection{Plus shaped slotted ftractal antenna}

For the 1st iteration, the antenna is resonating at frequencies $0.94 \mathrm{GHz}$ and $3 \mathrm{GHz}$ which are obtained from simulation and in practical the antenna is resonating at frequencies $1 \mathrm{GHz}, 2.94 \mathrm{GHz}$ and $3.12 \mathrm{GHz}$.
For the 2nd iteration, the antenna is resonating at frequencies $0.9 \mathrm{GHz}$ and $3.13 \mathrm{GHz}$ which is a dual band obtained from simulation and the practical result the antenna is resonating at the frequencies $0.94 \mathrm{GHz}$, $3.42 \mathrm{GHz}$ and $4 \mathrm{GHz}$ which is triple band.

\section{CONCLUSIONS}

The functioning of a fractal antennas are discussed in this paper and are found to have multi-band nature. In this paper, two types of fractal antennas are simulated, designed and tested. The triangular fractal antenna is fabricated for 2nd iteration where the resonant frequencies are obtained at $4.4 \mathrm{GHz}$ and $6.5 \mathrm{GHz}$ respectively. The plus shaped slotted fractal antenna obtained resonant frequencies at $0.94 \mathrm{GHz}, 3.43 \mathrm{GHz}$ and $4 \mathrm{GHz}$ on 2 nd iteration.

From the results, it can be concluded that on 2nd iteration the plus shaped slotted fractal antenna operates at three resonant frequencies while the triangular fractal antenna operated at two resonant frequencies. The reinforcement of the multiband behavior is accomplished using the triangular and plus shaped fractal antennas. These lineaments proved to be a boon as miniaturization with optimal behavior is achieved which once was considered a wild goose chase.

Hence these antennas can find application in wireless communication systems where size reduction is one of the key factors.

\section{REFERENCES}

[1] Hary Breed, 2009, "The Fundamentals of Patch Antenna Design and Performance", High Frequency Electronics, Summit Technical Media, LLC

[2] Douglas H. Werner and Suman Ganguly, "An Overview of Fractal Antenna Engineering Research," IEEE, Antennas and Propagation Magazine, Vol.45, No.1, 2003, 38-57

[3] K. Sing, V. Grewal and R. Saxena, "Fractal Antennas: A Novel Miniaturization Technique for Wireless Communications," International Journal of Recent Trends in Engineering, Vol. 2, No. 5, 2009, pp. 172-176.

[4] F. J. Jibrael and M. H. Hammed, "A New Multiband Patch Microstrip Plusses Fractal Antenna for Wireless Applications," ARPN Journal of Engineering and Applied Sciences, Vol. 5, No. 8, 2010, pp. 155-158.

[5] Vinoy. K J., "Fractal shaped antenna elements for wide and multi-band wireless applications Thesis, Pennsylvania, Aug. 2002

[6] Garg, Bhatia, Bahl, Ittipiboon, "Microstrip Antenna Design Handbook", Artech House, London, 2000.

[7] R. Kumar and P. Malathi, "Design of CPW -Fed Ultra wideband Fractal Antenna and Backscattering Reduction", Journal of Microwaves, Optoelectronics and Electromagnetic Applications, Vol. 9, No. 1, pp. 10-19, June 2010

[8] C. Puente, J. Romeu, R. Pous, X. Garcia, and F. Benitez, "Fractal multiband antenna based on the Sierpinski gasket," Electron. Lett., vol. 32, no. 1, pp.1-2, Jan. 1996 